\title{
Management of Potato Leafhopper, Empoasca fabae (Homoptera: Cicadellidae), on Alfalfa with the Aid of Systems Analysis
}

\author{
DAVID W. ONSTAD ${ }^{1}$ CHRISTINE A. SHOEMAKER, \\ AND BETH C. HANSEN
}

Department of Environmental Engineering, Hollister Hall, Cornell University, Ithaca, New York 14853

\begin{abstract}
Environ. Entomol. 13: 1046-1058 (1984)
ABSTRACT Efficient management of the potato leafhopper (Homoptera: Cicadellidae) on alfalfa requires a procedure for dealing with the complexities of the ecological and economic system. We developed a mathematical model to represent this agroecosystem and demonstrated how systems analysis can help to make management more efficient and less risky. Our management policies were based on two criteria: annual income calculated from the nutrient yields of three harvests, and level of carbohydrate reserve in the taproots at the end of the season. We determined the dynamic economic thresholds for controlling the leafhoppers as immigrants on each of the cuttings of alfalfa. During development of the thresholds we tested a variety of control tactics, including timing of harvests. We found that, for adult immigrants on the second crop, the economic thresholds increase exponentially as stem height increases. Tactics associated with these thresholds included insecticide treatments and early cutting of the second harvest. The results indicated that temperature pattern has an important effect on the economic thresholds and risk. Evaluation of the model and its results through sensitivity analysis, validation, and a comparison with current recommendations showed that the model can be a useful tool in research and management.
\end{abstract}

Alfalfa, Medicago sativa L., is a forage crop grown because of its high value as livestock feed. It is a perennial crop usually harvested three times during the spring and summer of each year in the northeastern United States. After winter dormancy, regrowth utilizing the carbohydrate reserves stored in the root begins in the spring, under the influence of the prevailing weather conditions.

The potato leafhopper, Empoasca fabae (Harris) (Homoptera: Cicadellidae), has been the most serious pest in alfalfa in the northeastern United States during the last decade. The adults immigrate into this region every summer from their overwintering sites in the south. Multiple, overlapping generations develop in the fields during the summer months, and all individuals die with the approach of winter. Stunting of alfalfa growth and reduction in the quantity and quality of harvest yields can result from damage to the translocation system in the plants, caused by leafhopper feeding.

Currently, the major tactics used to manage the potato leafhopper are cultural and chemical control techniques. Recently, the management of the leafhopper has been improved with the estimation of economic thresholds in several empirical studies (Hower and Byers 1977, Luna 1982, Wilson 1982). Our goal is to develop and use a general procedure for evaluating how thresholds should change as a

${ }^{1}$ Current address: Dept. of Entomology, N.Y. State Agric. Exp Stn., Geneva, NY 14456. function of weather and crop condition. Because of the complex population dynamics of the crop and the leafhopper and the inability to control weather, it is not feasible to determine empirically economic thresholds for all conditions. For this reason, we have constructed a mathematical model that describes the effects of management actions on leafhopper dynamics and crop losses. The model is a tool which we will use to investigate the influence of pest density, infestation period, weather, and crop condition on the choice of management policy (threshold and tactic). Sensitivity analysis will be used to evaluate the relative importance of processes that currently are not well understood.

\section{Methods and Models}

Our analysis of potato leafhopper management had three parts: (a) a crop growth model of alfalfa, (b) a population dynamics model of $E$. fabae, and (c) an economic analysis of crop loss and management action. Fig. 1 is a diagram of the combined model, EMPALF, which consists of parts (a) and (b). For part (a) we used a modified version of the alfalfa simulation model, ALSIMl (Level 2), developed by Fick (1981). The following three subsections describe the structure of the leafhopper submodel (part b), that we created, the equations that we used to connect the two submodels, and the procedure used in the economic analysis.

Creation of the Leafhopper Model. We mod- 


\section{Potato Leofhopper Model}

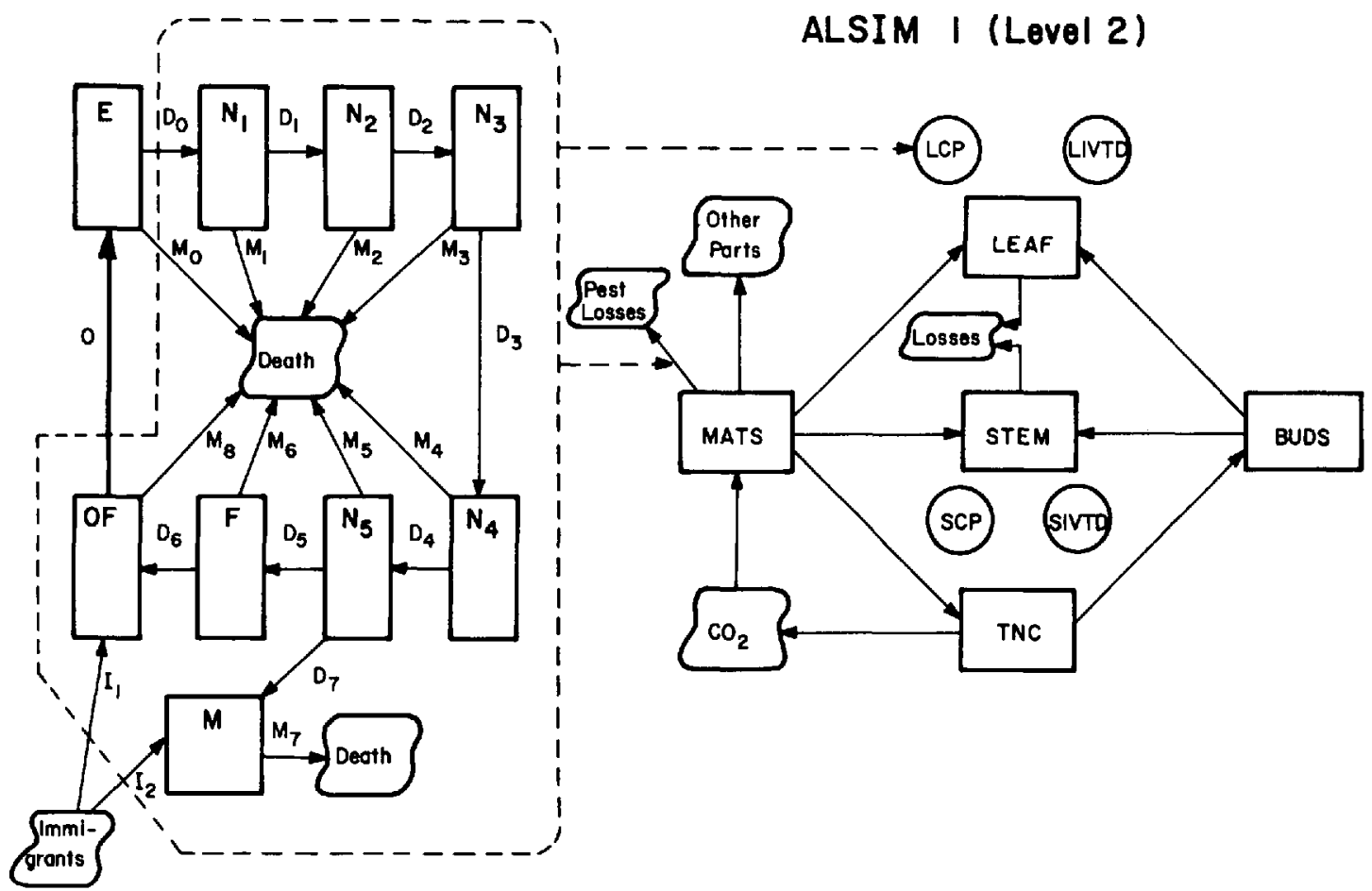

Fig. 1. Relational diagram of the components of EMPALF (model of Empoasca fabae on alfalfa). The leafhopper population is represented by states for eggs $(E)$, nymphs $\left(N_{1}-N_{s}\right)$, males $(M)$, females $(F)$, and ovipositing females (OF). The population dynamics are described by the rates of development $\left(\mathrm{D}_{\mathrm{i}}\right)$, mortality $\left(\mathrm{M}_{i}\right)$, oviposition (O), and immigration (I). The state variables of ALSIM1 (Level 2) represent parts of the alfalfa crop: MATS (materials available for top growth and storage), LEAF (leaves), STEM (stems), TNC (total nonstructural carbohydrates in the taproots), and BUDS (basal buds for regrowth). The processes are described by rate equations that simulate the transfer of material among the parts of the crop. Variables for crude protein (LCP, SCP) and in vitro true digestibility (LIVTD, SIVTD) represent crop quality. The leafhopper population reduces MATS and the concentration of LCP.

eled the phenological development of nine stages in the leafhopper's life cycle as a distributed delay process (Manetsch 1976). In this process, the life stages are state variables (leafhoppers per $\mathrm{m}^{2}$ ), and the stochastic rates of development are defined by their means and variances. We derived functions for seven of these rates by analyzing data supplied by Simonet (Simonet and Pienkowski 1980) using linear regression. For eggs and nymphs, the data indicated that the mean rate could be adequately described by a degree-day function of the form:

$$
\begin{array}{ll}
\text { rate }=0 & \text { if } T<T_{\text {base }} \\
\text { rate }=a\left(T-T_{\text {bass }}\right) & \text { if } T_{\text {base }} \leq T<T_{\max } \\
\text { rate }=a\left(T_{\max }-T_{\text {base }}\right) & \text { if } T \geq T_{\max }
\end{array}
$$

where $T$ is temperature, $T_{\text {base }}$ is the lowest temperature for development, and $T_{\max }$ is temperature for maximum development. The coefficients and statistics for each line are given in Table 1 . The values of $T_{\max }$ were estimated from the relationships between the rates of the two highest tem- peratures. For the adult female in the preoviposition period, the following quadratic function gave a better fit to the three data points than did a linear function:

$$
\begin{aligned}
\text { developmental rate }= & -0.496+0.0639 T \\
& -0.0015 T^{2} \geq 0
\end{aligned}
$$

\begin{tabular}{|c|c|c|c|c|c|}
\hline \multirow[b]{2}{*}{ Stage } & \multicolumn{4}{|c|}{ Parameter value } & \multirow{2}{*}{$\begin{array}{l}T_{\max } \\
\left({ }^{\circ} \mathrm{C}\right)\end{array}$} \\
\hline & $a$ & $\begin{array}{l}T_{\text {base }} \\
\left({ }^{\circ} \mathrm{C}\right)\end{array}$ & $\begin{array}{l}\text { Data } \\
\text { points }\end{array}$ & $R^{2}$ & \\
\hline Egg & 0.0074 & 7.6 & 4 & 0.99 & 32.2 \\
\hline First instar & 0.0251 & 6.89 & 4 & 0.97 & 29.4 \\
\hline Second instar & 0.039 & 8.74 & 5 & 0.99 & 35.0 \\
\hline Third instar & 0.0451 & 10.1 & 4 & 0.98 & 32.2 \\
\hline Fourth instar & 0.0338 & 9.2 & 4 & 0.99 & 29.4 \\
\hline Fifth instar & 0.017 & 7.0 & 5 & 0.95 & 35.0 \\
\hline
\end{tabular}

Table 1. Parameters describing the rate of development of $E$. fabae as a function of temperature for $T_{\text {base }} \leq T \leq T_{\max }$, based on data from Simonet and Pienkowski (1980) 
Although this curve fits the data very well, the validity of equation 2 is uncertain, since DeLong (1938) observed that the preoviposition period is shorter in the field than in the laboratory. We used the average lifespan determined by DeLong (1938), which is 33 days, for the longevity of the male and ovipositing female adults.

In our model, oviposition occurs throughout the lifetime of the ovipositing female; thus its duration is independent of temperature. We assumed that oviposition does not occur in the stubble during the first 3 days after a cut. From an analysis of observations made by Simonet (1978a) on beans, we determined that the rate of oviposition is a quadratic function of an adult female"s physiological age, with peak oviposition occurring at the middle of a female's lifetime. The following equation calculates the oviposition rate at its optimal temperature $\left(23.9^{\circ} \mathrm{C}\right)$ :

$$
\text { OVIP }=907.2 A-907.2 A^{2}
$$

where OVIP is eggs/female/physiological time and $A$ is physiological age between 0 and 1 . Integration of this function over the whole oviposition period produces the maximum fecundity of 151 eggs per female at $23.9^{\circ} \mathrm{C}$. This value is based on three studies. DeLong (1938) and Simonet (1978a) observed a maximum fecundity of 240 eggs per female on beans, but Kieckhefer and Medler (1964) found that fecundity was $37 \%$ less on alfalfa in comparison to beans. From an analysis of another part of the study by Kieckhefer and Medler (1964), we determined how much the oviposition rate (equation 3 ) should be reduced at daily mean temperatures above or below $23.9^{\circ} \mathrm{C}$.

From data collected by Simonet (1978a) in the laboratory, we calculated survival rates of 0.88 , $0.97,0.96,0.96$, and 0.92 for the five nymphal stages when the temperature is between 0 and $35^{\circ} \mathrm{C}$. For temperatures above $35^{\circ} \mathrm{C}$, these rates fall to $0.67,0.89,0.88,0.77$, and 0.47 , and below $0^{\circ} \mathrm{C}$ mortality is $100 \%$. In the model, survival per stage is converted to survival per time step. We assume that egg survival is $100 \%$ except when harvesting occurs; in this case egg survival is $0 \%$ since the eggs are laid in the parts of the plant removed during harvest.

Harvest mortality of nymphs and adults is a combination of several factors. Nymphs can die because of injury or exposure to adverse environmental conditions. They can also be removed with the hay. Adults can die from injury during tractor operation, but the primary reason for the decline in density is emigration. For nymphs, Simonet and Pienkowski (1979) determined that survival after about a week was $5 \%$, depending on conditions at the harvest. The only information on harvest mortality for adults was published by Pienkowski and Medler (1962). Their data indicated that the number of individuals in the field 2 weeks after harvest was about $17 \%$ of the individuals present before harvest. Since immigration could have occurred during this time, this percentage does not neces- sarily reflect the harvest survival rate. We therefore estimated the harvest survival by calibrating the model to field data collected by William Lamp in Urbana, Ill. (Illinois Natural History Survey, Champaign, unpublished data). The best estimate for survival was $8 \%$ of the adults about 6 days after harvest.

Based on these assumptions, we created the following function to mimic the survival rates of nymphs and adults:

$$
\text { harvest survival }=[C+\operatorname{LEAF}(t)] / 2 C
$$

where LEAF is the biomass of leaves in the stubble on day $t$ and $C$ is $13 \mathrm{~g} / \mathrm{m}^{2}$. This equation reduces the densities by $50 \%$ on the first day and then calculates higher and higher survival rates until the leaf biomass exceeds $13 \mathrm{~g} / \mathrm{m}^{2}$, which represents stubble $10 \mathrm{~cm}$ high according to Bula and Hintz (1978). Thus, equation 4 distributes mortality over a period of about a week in New York in such a way as to mimic losses due to injury and removal just after the cut, and to mimic environmentally linked mortality during subsequent days until the stubble can provide adequate refuge for the nymphs and adults. This simple method should be adequate to simulate situations in which fields are properly mowed. However, when harvesting produces stubble taller than desired, or when haycrop silage production is being modeled, more complex functions might be needed.

We based the function for mortality due to insecticide on data collected by Gauthier (1978) using malathion and methoxychlor, and by Simonet (1978b) and Huggans et al. (1980) using malathion. In the following equation we assume that nymphs and adults are affected in the same manner

$$
\begin{aligned}
& \text { insecticide mortality }=0.5 \exp (-0.1 t) \text {, } \\
& \text { for } t \leq 7
\end{aligned}
$$

where the daily rate declines as a function of the days since application, $t$. After the 8-day period, cumulative survival is $3 \%$; a low estimate which does not consider the influence of precipitation or inadequate application techniques. Using equation 5 in a simple 8-day simulation, we were able to compare our results to the three values of cumulative survival given in the three reports. The regression of observed against predicted values produced a line $(y=-0.029+1.16 x)$ which had an $R^{2}$ of $85 \%$. Because the intercept and the slope were not significantly different from 0 and 1 , respectively, we accepted equation 5 as an adequate model of mortality due to insecticide.

Because we focused primarily on within-field population dynamics, the model does not predict adult migration. Instead, we assumed that immigration into the field occurs uniformly over a 5-day period. We used the model to examine the influence of timing of immigration on management practices. We assumed that the female immigrants are fertile and capable of oviposition upon arrival (DeLong 1971). In the model, we used a 
sex ratio of $80: 20$ (females to males) for the immigrants and 50:50 for their offspring (Medler et al. 1966, Decker et al. 1971).

Coupling the Insect and Plant Models. To simulate the damage caused by $E$. fabae, the submodel described above was coupled to a modified version of ALSIM1 (Level 2). This model of alfalfa crop growth simulates the production and flow $\left(\mathrm{g} / \mathrm{m}^{2}\right)$ of photosynthate, leaf biomass, stem biomass, biomass in the buds, and total nonstructural carbohydrates (TNC) stored in the root (Fick 1981). The modified version includes four equations that calculate the proportions of crude protein and in vitro true digestibility in the leaves and stems using degree-days (Onstad and Fick 1983). We modeled the direct effects of the leafhopper on photosynthate production and on crude protein level in the leaves, and indirect effects on total digestibility (through changes in the leaf : stem ratio) and TNC. We assumed that there is no significant effect on stem crude protein.

In several laboratory experiments, Zaky (1981) quantified the relationship between leafhopper density and loss in dry weight caused by certain life stages, as well as the relationship between loss in dry weight and stem height at the start of an infestation. Because we needed a single function to calculate the daily damage rate for any possible set of conditions, we had to fit our whole simulation model (EMPALF) to her data. When the following equation was incorporated into the model, we were able to calibrate EMPALF by performing simulations with the same life stages, the same densities, and for the same periods of alfalfa development studies by Zaky (1981):

$$
L Y(t)=0.45 \ln \left[1+\frac{\operatorname{PLHDAY}(t)}{100 \cdot \operatorname{LEAF}(t)+1}\right]
$$

where $L Y$ is the daily proportional loss in photosynthate available for top growth and storage, PLHDAY is a density-days variable, LEAF is leaf biomass, and $t$ is time. In the calibration, five of Zaky's observations of damage taken at three stem heights (with three leafhopper densities at the middle height) were regressed against the losses calculated by the model using equation 6 . The regression line $(y=0.007+1.04 x)$ had an $R^{2}$ of $97 \%$. The intercept and slope were not significantly different from 0 and 1 , respectively. These results indicate that this was an adequate method for simulating the effect of potato leafhoppers on alfalfa as observed by Zaky.

Several assumptions were made in the development of equation 6. Because Zaky (1981) had observed that damage by the leafhopper leveled off at high densities, we assumed that: (1) once a leaf has been injured, future attacks cause less and less additional loss in photosynthate production in and translocation out of the leaf; and (2) in the field, the amount of canopy escaping attack increases as leaf biomass increases for a given leafhopper density. For these reasons, we chose leaf biomass to represent the capacity of the crop to withstand attack, instead of stem height. In addition, stem height is not calculated by ALSIMl (Level 2). In equation 6 , the damage rate does decline as leaf biomass increases. Furthermore, the model produces a leveling-off in the damage to yield as the leafhopper density increases, just as Zaky's data indicated. We have added a temporal influence by using density-days (PLHDAY) instead of density alone. This followed from our assumption that, at a given alfalfa growth stage, the number of previous attacks on the canopy, not just the previous density of attackers, determines the damage rate for a day.

Information reported by Flinn (1981) enabled us to determine the relative importance of each of the life stages in terms of damage to alfalfa. Since we calibrated equation 6 using the density of thirdthrough fifth-instar nymphs (according to Zaky's data), we gave these stages weights of 1 and compared the other stages to the activity of these large nymphs. We estimated that the first and second instars and the adult males cause $75 \%$ as much damage (biomass and leaf protein losses) as the larger nymphs, and that the adult females (both stages) cause $125 \%$ as much damage. Data collected by Ladd and Rawlins (1965) support this weighting system. The model multiplies the eight life stages by the appropriate weights to calculate the total effective density of leafhoppers per $\mathrm{m}^{2}$ on alfalfa for each day (PLH). The variable PLHDAY is the sum of the values of PLH from the beginning of immigration or the fourth day after the previous cutting of the crop.

To compute the losses in the proportion of leaf crude protein (LCP), we used the following relationship derived by Zaky (1981):

$$
\begin{aligned}
\log _{10} \mathrm{CP}(t)= & 1.62-0.1,2 \times \\
& \log _{10}[1+\operatorname{PLH}(t) / 200]
\end{aligned}
$$

where CP is the percentage of leaf crude protein remaining after a 5-day infestation with a density of PLH/200, which is the effective density of leafhoppers per three stems. After CP is calculated, our model computes the proportional loss in leaf crude protein (REDLCP):

$$
\operatorname{REDLCP}(t)=[0.42-0.01 \mathrm{CP}(t)] / 0.42
$$

where 0.42 is the maximum value of LCP normally observed. To determine the daily proportional loss in LCP the model must divide REDLCP by 5 . Because we assumed that this daily loss decreases when an infestation continues at extremely high densities, the equation for the daily proportional loss RLCP is:

$$
\begin{gathered}
\operatorname{RLCP}(t)=\frac{\operatorname{REDLCP}(t)}{5} \cdot \operatorname{minimum}(1, \mathrm{~K}) \\
\text { for } \mathrm{K}=\frac{24,000}{\operatorname{PLHDAY}(t)+1}
\end{gathered}
$$

where the 24,000 leafhopper-days are equivalent to 24 leafhoppers per three stems for 5 days. The 
final step in the computation of the proportion of LCP in the harvested crop is:

$$
\mathrm{LCP}_{H}=\mathrm{LCP}_{P}(1-\mathrm{SRLCP})
$$

for

$$
\mathrm{SRLCP}=\sum_{i=b}^{c} \operatorname{RLCP}(t)
$$

where $b$ is the fourth day after the previous harvest, $c$ is the present cut time, and LCP $_{p}$ is the predicted value for leaf crude protein in the absence of leafhoppers. The model does not permit $\mathbf{L C P}_{H}$ to fall below the level of stem crude protein at the harvest.

An implicit assumption in the development of the damage equations (equations 6 and 7 ) is that the leafhopper population is distributed uniformly within a field. Since damage levels off at higher densities on individual plants, an aggregated population would tend to cause less damage than one that was uniformly distributed. Kieckhefer and Medler (1966) did observe leafhopper populations aggregating in the margins of fields.

Economic Analysis of the Coupled Model (EMPALF). To determine the economic value of the crop, we used the procedure of Onstad and Shoemaker (1984). This procedure calculates the price of stored hay relative to a reference-forage price by comparing the quality of each. In this study, the price of the reference forage $(60 \%$ alfalfa, $40 \%$ grass) was $\$ 66 / \mathrm{Mg}$, which was the average price in New York from 1979 to 1981 . The cost of an insecticide application was $\$ 37 / \mathrm{ha}$, based on 1982 prices. We assumed that the chemical cost was $\$ 24.70 / \mathrm{ha}$, or $67 \%$ of the total, with an additional charge for aerial application equaling $33 \%$.

We simulated the population dynamics of $E$. fabae and the growth of the alfalfa crop from 1 April to the end of September. The alfalfa submodel, ALSIM1 (Level 2), had a time step of 1 day, and the distributed delay model used to compute the leafhopper's dynamics (seventh order delay for each life stage) had a time step of $1 / 10$ of a day. All simulations used to produce the management policies and to perform the sensitivity analyses were computed with average precipitation and solar radiation data for Ithaca, N.Y. We studied the influence of temperature by using three patterns, which were chosen based on the sum of degree-days above $10^{\circ} \mathrm{C}$ from May to September. The low (837 degree-days), medium (983), and high $(1,179)$ patterns represent the range observed in central New York since 1971.

In our analysis, we attempted to determine the management policies (thresholds and tactics) that would produce high net incomes from three harvests, and result in adequate levels of carbohydrate reserves (TNC) in the taproot at the end of the growing season. We did not optimize separate cuttings. Instead, we followed the same general approach used in a previous study (Onstad and Shoemaker 1984), in which the optimal cutting schedule for alfalfa forage produced in the Northeast was determined. The timing of the first harvest (based on degree-days) was chosen to maximize total income and final TNC level for a season. Because Pienkowski and Medler (1962) demonstrated that changing the time of the first harvest was not an effective method for managing the leafhopper, we made the first harvest at the time suggested by the Onstad and Shoemaker study for the temperature pattern in question.

\section{Results}

The simulation results indicated that management policies were affected by a number of factors including weather, time of immigration, density of adult immigrants, and developmental stage of the crop. For each weather pattern, we simulated the economic effects of various densities of immigrants arriving at different growth stages (stem heights) of the first, second, or third crops cut during a season. From the results, we identified the dynamic thresholds and tactics that improved management the most. The economic threshold is the sampled density above which the costs of more effective control measures are less than the losses due to increased damage to all alfalfa crops. Thus, the characteristics of the available tactics influence the calculation of the economic thresholds. In our analysis of management of immigrants on the second crop, we studied five different tactics: (1) traditional postarrival treatment of the adult immigrants with an insecticide, (2) treatment of the stubble after the second harvest, (3) both postarrival and postharvest treatments, (4) cutting of the second crop 1 week early, and (5) cutting of the second crop early followed by treatment of the stubble with an insecticide. No other combinations of tactics tested were as good as these five. In all cases, we assumed that sampling occurred at the end of the immigration period.

Determination of Management Policies. Fig. 2 gives the computed economic thresholds and their associated tactics for leafhoppers immigrating into a field after the first harvest. These thresholds are defined as the lowest pest densities at which control is required. As indicated in Fig. 2, the thresholds vary with alfalfa biomass (leaves and stems) and temperature. The biomass of the top growth calculated by the model was converted to stem height using the relationships derived by Bula and Hintz (1978). Three patterns are clear in this figure. First, the economic thresholds increase rapidly after the alfalfa reaches $30 \mathrm{~cm}$ in height. This result was expected, because Zaky's (1981) data indicated that mature stages of alfalfa were less vulnerable. Second, the economic thresholds based on the three temperature patterns are similar at low stem heights but diverge more and more as stem height increases. This demonstrates that weather after an immigration can have an important (yet uncertain) effect on the outcome of any decision. Third, for a given stem height, the tactic 


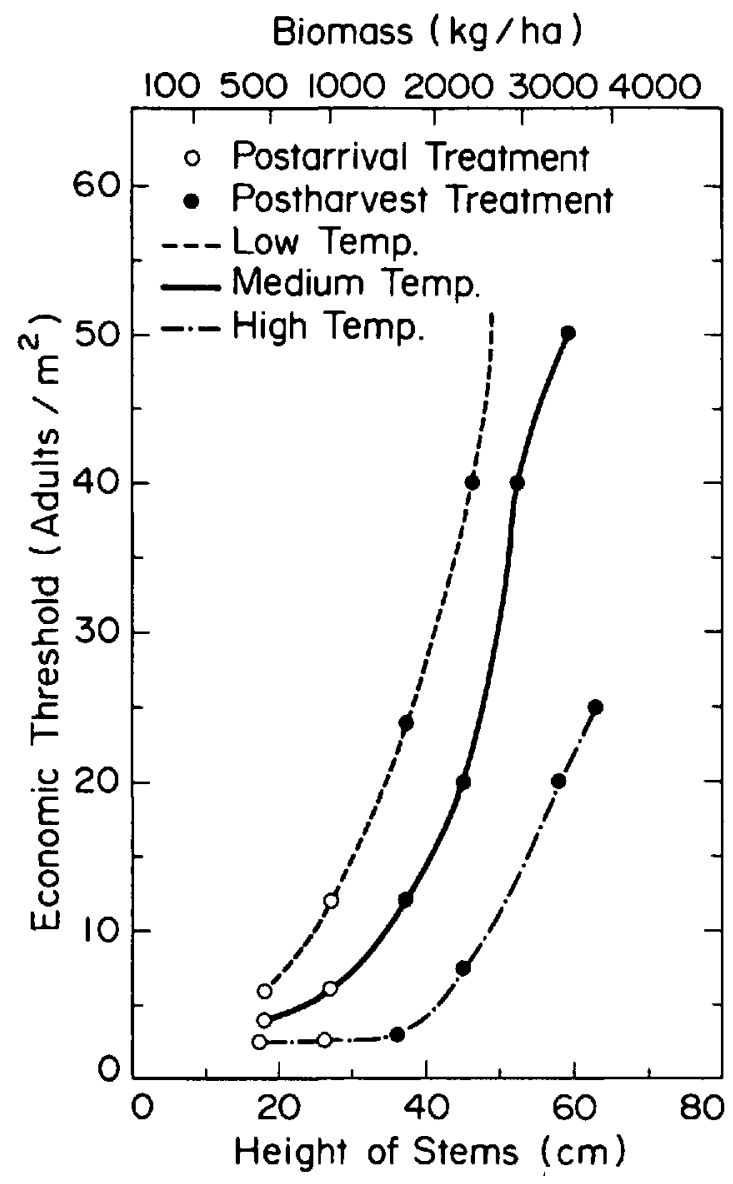

Fig. 2. Economic threshold for E. fabae on the second crop of alfalfa as a function of stem height or biomass at the time of sampling for the adult immigrants under three seasonal temperature patterns for New York.

associated with the economic threshold is the same for all three temperature patterns, but the tactic changes from postarrival to postharvest treatment as the stem height increases. Note that the thresholds take into account the damage to the second and third crops caused by the immigrants and their offspring, and thus no other thresholds are needed for the next crop unless another immigration occurs.

Fig. 2 shows the minimum density at which some management action must be taken. However, for a given alfalfa stem height, the best tactic to use may change as the density of immigrating leafhoppers increases. Thus, multiple economic thresholds may be required for efficient management at each growth stage. Fig. 3 illustrates how these policies change for the medium temperature pattern. For example, if the immigration occurs when the alfalfa is $45 \mathrm{~cm}$ high, the best policies are: do nothing if the density is less than 20 leafhoppers per $\mathrm{m}^{2}$, make a postharvest treatment if the density is between 20 and 35 leafhoppers per

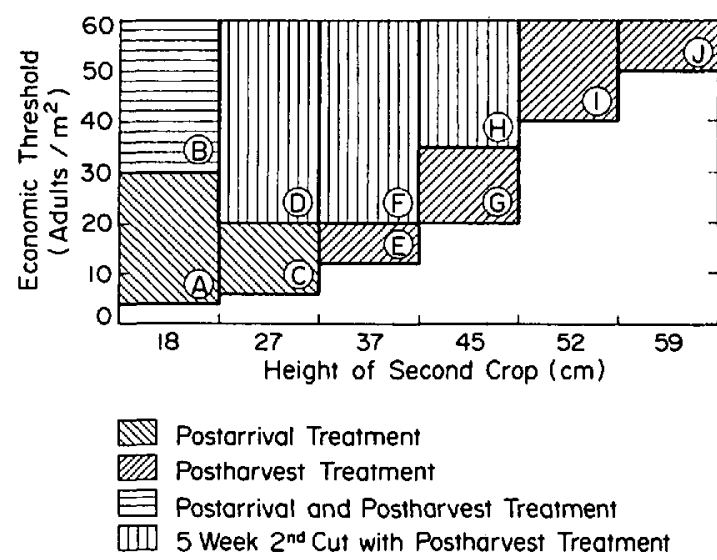

Fig. 3. Economic thresholds and tactics for the management of $E$. fabae on the second crop of alfalfa under a medium temperature pattern for New York. The policies are a function of stem height at the time of sampling for the adult immigrants.

$\mathrm{m}^{2}$, or harvest the second crop early and make a postharvest treatment if the density exceeds 35 leafhoppers per $\mathrm{m}^{2}$.

Fig. 3 indicates that when the crop is relatively short $(18-27 \mathrm{~cm})$, a postarrival treatment is preferable to a postharvest treatment when leafhopper densities are low. An insecticide treatment after the arrival of the immigrants ( 7 days after the first day of immigration; 2 days after sampling) protects the second crop very well, but it does not reduce the number of offspring already oviposited before the treatment. Hence, a treatment after the second harvest (4 days after the cut) usually protects the third crop better by killing more of the offspring after they have matured into the susceptible adult and nymphal stages. This explains why an extra postharvest treatment is needed for high densities on 18-cm alfalfa. For more mature alfal$\mathrm{fa}$, protection of the second crop is less important relative to the third crop. Therefore, the lower threshold for $37-\mathrm{cm}$ alfalfa requires a postharvest treatment (for control of leafhopper on the third crop) and not a postarrival application as used for the $27-\mathrm{cm}$ crop.

When the leafhopper infestation is light, the optimal cutting schedule in New York requires 6-week cutting intervals. However, when the density of immigrants is high and the second crop is in the middle of its growth period, Fig. 3 indicates that the best tactic is to cut the second crop after 5 weeks (early second cut with postharvest treatment) and retain the 6-week interval for the third crop. The early second harvest interrupts the development of the offspring before many can become nymphs and adults. This is important, because only these two stages can survive the harvest. Pienkowski and Medler (1962) recommended cutting the second crop early to manage leafhoppers in Wisconsin. Note, however, that cutting the sec- 
Table 2. Results computed by EMPALF with the medium temperature pattern using the policies presented in Fig. 3 for densities of adult immigrants sampled at the given alfalfa stem heights

\begin{tabular}{|c|c|c|c|c|c|c|c|c|c|c|}
\hline \multirow[b]{2}{*}{ Policy } & \multirow{2}{*}{$\begin{array}{c}\text { Stem } \\
\text { height } \\
\text { (cm) }\end{array}$} & \multirow{2}{*}{$\begin{array}{c}\text { Adults/ } \\
\mathrm{m}^{2}\end{array}$} & \multicolumn{2}{|c|}{ End of season } & \multicolumn{3}{|c|}{ Second crop } & \multicolumn{3}{|c|}{ Third crop } \\
\hline & & & $\begin{array}{c}\text { Income }^{a} \\
(\$ / h a)\end{array}$ & $\mathrm{TNC}^{b}$ & $\begin{array}{c}\text { Yield } \\
(\mathrm{Mg} / \mathrm{ha})\end{array}$ & $\begin{array}{c}\text { Leaf } \\
\text { protein }\end{array}$ & $\begin{array}{c}\text { Leaf } \\
\text { fraction }^{d}\end{array}$ & $\begin{array}{c}\text { Yield } \\
\text { (Mg/ha) }\end{array}$ & $\begin{array}{c}\text { Leaf } \\
\text { protein }\end{array}$ & $\begin{array}{c}\text { Leaf } \\
\text { fraction }\end{array}$ \\
\hline 一 & - & 0 & 915 & 0.39 & 4.16 & 0.29 & 0.48 & 3.54 & 0.30 & 0.46 \\
\hline $\begin{array}{l}\text { A } \\
\text { B }\end{array}$ & $\begin{array}{l}18 \\
18\end{array}$ & $\begin{array}{r}4 \\
30\end{array}$ & $\begin{array}{l}854 \\
794\end{array}$ & $\begin{array}{l}0.39 \\
0.39\end{array}$ & $\begin{array}{l}4.15 \\
4.10\end{array}$ & $\begin{array}{l}0.27 \\
0.22\end{array}$ & $\begin{array}{l}0.48 \\
0.49\end{array}$ & $\begin{array}{l}3.53 \\
3.53\end{array}$ & $\begin{array}{l}0.26 \\
0.26\end{array}$ & $\begin{array}{l}0.46 \\
0.46\end{array}$ \\
\hline $\begin{array}{l}\mathrm{C} \\
\mathrm{D}\end{array}$ & $\begin{array}{l}27 \\
27\end{array}$ & $\begin{array}{r}6 \\
20\end{array}$ & $\begin{array}{l}847 \\
825\end{array}$ & $\begin{array}{l}0.38 \\
0.33\end{array}$ & $\begin{array}{l}4.15 \\
3.31\end{array}$ & $\begin{array}{l}0.26 \\
0.24\end{array}$ & $\begin{array}{l}0.48 \\
0.56\end{array}$ & $\begin{array}{l}3.52 \\
3.68\end{array}$ & $\begin{array}{l}0.25 \\
0.27\end{array}$ & $\begin{array}{l}0.46 \\
0.48\end{array}$ \\
\hline $\begin{array}{l}\mathbf{E} \\
\mathbf{F}\end{array}$ & $\begin{array}{l}37 \\
37\end{array}$ & $\begin{array}{l}12 \\
20\end{array}$ & $\begin{array}{l}843 \\
841\end{array}$ & $\begin{array}{l}0.39 \\
0.33\end{array}$ & $\begin{array}{l}4.14 \\
3.33\end{array}$ & $\begin{array}{l}0.23 \\
0.27\end{array}$ & $\begin{array}{l}0.48 \\
0.56\end{array}$ & $\begin{array}{l}3.53 \\
3.70\end{array}$ & $\begin{array}{l}0.27 \\
0.27\end{array}$ & $\begin{array}{l}0.46 \\
0.48\end{array}$ \\
\hline $\begin{array}{l}\mathrm{G} \\
\mathrm{H}\end{array}$ & $\begin{array}{l}45 \\
45\end{array}$ & $\begin{array}{l}20 \\
35\end{array}$ & $\begin{array}{l}848 \\
845\end{array}$ & $\begin{array}{l}0.39 \\
0.33\end{array}$ & $\begin{array}{l}4.14 \\
3.34\end{array}$ & $\begin{array}{l}0.25 \\
0.28\end{array}$ & $\begin{array}{l}0.48 \\
0.56\end{array}$ & $\begin{array}{l}3.53 \\
3.70\end{array}$ & $\begin{array}{l}0.27 \\
0.27\end{array}$ & $\begin{array}{l}0.46 \\
0.48\end{array}$ \\
\hline $\begin{array}{l}\text { I } \\
\text { J }\end{array}$ & $\begin{array}{l}52 \\
59\end{array}$ & $\begin{array}{l}40 \\
50\end{array}$ & $\begin{array}{l}849 \\
855\end{array}$ & $\begin{array}{l}0.39 \\
0.39\end{array}$ & $\begin{array}{l}4.14 \\
4.15\end{array}$ & $\begin{array}{l}0.25 \\
0.27\end{array}$ & $\begin{array}{l}0.48 \\
0.48\end{array}$ & $\begin{array}{l}3.52 \\
3.53\end{array}$ & $\begin{array}{l}0.26 \\
0.26\end{array}$ & $\begin{array}{l}0.46 \\
0.46\end{array}$ \\
\hline
\end{tabular}

Net income for three harvests (income - treatment cost)

$b$ Proportion of total nonstructural carbohydrates in $10 \mathrm{~cm}$ of taproot with biomass of $250 \mathrm{~g} / \mathrm{m}^{2}$ at the end of September (day 270 )

$c$ Proportion of crude protein in the leaves.

$d$ Leaf biomass divided by total top growth.

ond crop early tends to produce lower TNC levels at the end of the season.

This reduction in carbohydrate reserves is shown in the TNC column of Table 2 for policies D, F, and $\mathrm{H}$ from Fig. 3 . Although it is lower than the maximum shown in the table, a level of $33 \%$ is still acceptable under most conditions (Onstad and Shoemaker 1984). Under these three policies, low yields in the second harvest are compensated for by higher quality in the second crop (leaf fraction) and higher yield at the third harvest. However, for the other situations, income is lost primarily by reduction in the leaf crude protein level. Even at low population densities, the value of the crops can be significantly affected by this damage. In fact, some of this loss cannot be prevented because of the difficulties in controlling the production and development of offspring after adult immigration, as well as in controlling the immigrants. Because each insecticide treatment costs $\$ 37 /$ ha, no treatment will be recommended until the predicted loss at least equals that cost.

Figs. 2 and 3 considered management of leafhoppers when immigration occurs after the first harvest. Table 3 presents the policies for the management of the leafhopper on the season's first crop of alfalfa (taking into account damage to the sub-

Table 3. Best policies for the management of $E$. fabae on a season's first crop of alfalfa under a medium temperature pattern for New York

\begin{tabular}{|c|c|c|}
\hline $\begin{array}{l}\text { Stem } \\
\text { height } \\
\text { (cm) }\end{array}$ & $\begin{array}{c}\text { Thresh- } \\
\text { old }^{\circ}\end{array}$ & Tactic \\
\hline 49 & 30 & Treat with insecticide after sampling \\
\hline 56 & 25 & Treat with insecticide after sampling \\
\hline 63 & 20 & Treat after the first harvest \\
\hline 68 & $20^{b}$ & Treat after the first harvest \\
\hline
\end{tabular}

a Adult immigrants per $\mathrm{m}^{2}$ sampled at the given stem height.

${ }^{b}$ Equivalent to observing two adults per $\mathrm{m}^{2}$ after the harvest. sequent crops). Again, only the results of the simulations under a medium temperature pattern are presented; the low pattern requires higher thresholds, the high temperature pattern lower ones. Several factors cause the threshold to be higher at $49 \mathrm{~cm}$ than with taller crops. The earlier immigrants (occurring before $49 \mathrm{~cm}$ ) cause little damage to the first crop, and oviposition after the first harvest by earlier immigrants is less than by later immigrants.

The treatment threshold for managing immigrants on the third crop is between 20 and 50 leafhoppers per $\mathrm{m}^{2}$ during the second week after the second harvest. If income for the current year was the only criterion, then 50 adults per $\mathrm{m}^{2}$ would be the threshold. However, serious losses in TNC occur at densities below 50 adults per $\mathrm{m}^{2}$, especially under a high temperature pattern.

In a simulation study of the influence of multiple immigration periods on management, we found that the second influx can usually be managed using the same set of policies recommended for single immigrations. One exception is the situation in which the immigration periods are separated by many weeks and the densities of both groups of immigrants are just below their economic thresholds. In this case, the model should be simulated with these conditions to determine if more stringent control measures (other than those normally recommended) are required.

Validation. Before model-generated policies can be used under commercial conditions, their usefulness and validity must first be evaluated. Both ALSIMI (Level 2) and the functions for calculating crude protein and digestibility levels have been compared to data collected in New York and have been found to give an adequate description of field observations (Fick 1981, Onstad and Fick 1983). No field data were available to test the validity of the harvest yields and TNC levels predicted by the model for conditions with leafhopper infesta- 


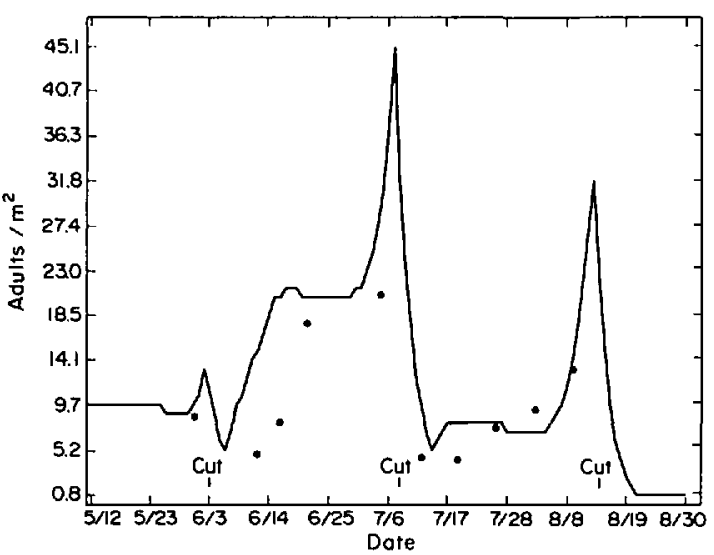

Fig. 4. Simulated (curve) and observed (points) densities of potato leafhopper adults on alfalfa for field 967 in Todd County, Ky., in 1980.

tions. To evaluate the population dynamics submodel for the leafhopper, we obtained field data from Kentucky and Illinois.

Grayson Brown provided data collected by IPM scouts in 1980 for nine alfalfa fields (Dept. of Entomology, Univ. of Kentucky, unpublished data). The nine sets consisted of from 8 to 10 observations of total number of leafhoppers per 100 sweeps collected over periods of from 8 to 10 weeks. We assumed that the data represented adult densities, since nymphs are difficult to sample with sweep nets. Based on information in a report by Cherry et al. (1977), we converted adults per 100 sweeps to adults per $\mathrm{m}^{2}$. A major problem was choosing observation dates, because the Kentucky IPM data were labeled only according to the week during which the samples were collected. Therefore, the observation points in Fig. 4 could be off by 2 or more days.

Fig. 4 presents the simulated and observed

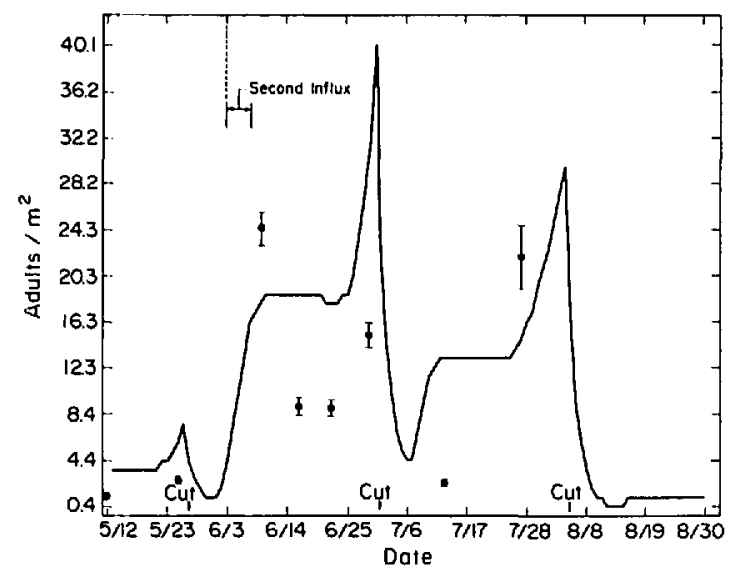

Fig. 5. Simulated (curve) and observed (points \pm standard error) densities of potato leafhopper adults on alfalfa for untreated fields in Belleville, Ill., in 1982.

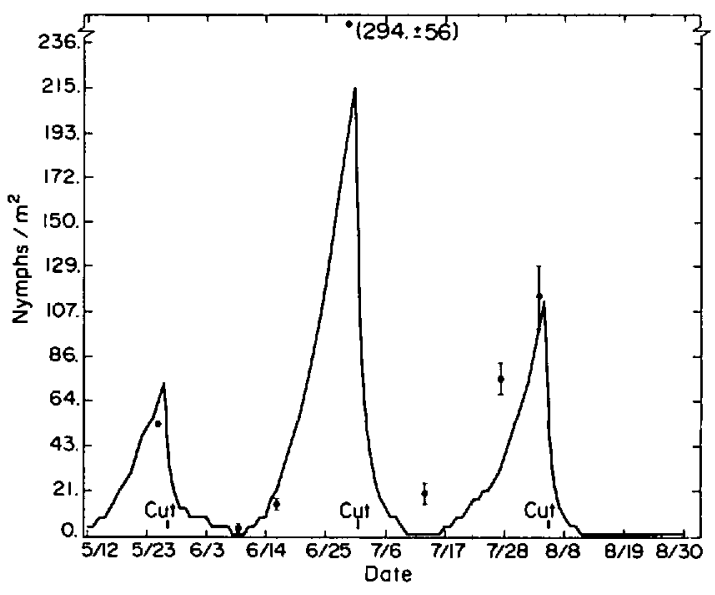

Fig. 6. Simulated (curve) and observed (points \pm standard error) densities of potato leafhopper nymphs on alfalfa for untreated fields in Belleville, Ill., in 1982.

densities of adults for one of the fields in Kentucky. According to the computer records in Kentucky, these fields were not treated with an insecticide while the leafhoppers were present. Since the density of immigrating leafhoppers was not known, the parameter in the model describing the number of immigrating adults was adjusted to fit the first data point. Although there is a reasonably good fit in Fig. 4, it is not typical of the Kentucky validation data. The differences between the observed and simulated were greater in the other comparisons.

William Lamp (Illinois Natural History Survey, Champaign) provided data from two field experiments conducted during 1982 in Illinois. In both experiments, adults were sampled with a D-Vac suction device and nymphs were sampled by collecting stems in cartons by the method of Simonet et al. (1978). At Belleville, eight observations of adults were taken over a 76-day period and seven observations of nymphs were made over a 70-day period in both treated and untreated plots. Using information supplied by William Lamp, we converted the densities to number of individuals per $\mathrm{m}^{2}$ for each stage. For the Kentucky IPM data, the precision of the observations was unknown. For the Illinois data, we were able to calculate the standard errors of the means.

Figs. 5 and 6 compare model predictions to observations of both adults and nymphs made in untreated plots at Belleville, Ill. In this case, the data indicated there was a large second immigration after 3 June because there were unusually high densities of both adults and nymphs after this date. As before, the number of immigrating adults was estimated by calibrating the model to the first observation of adults. Our comparisons of the simulated and observed densities for the treated plots at Belleville resulted in a deviation that could not be explained. Even after a second insecticide treat- 
Table 4. Changes in the economic thresholds (adults $/ \mathrm{m}^{2}$ ) presented in Fig. 3 resulting from modifications of model functions, plus the maximum loss in income $(\$ / h a)$ due to use of the original policy

\begin{tabular}{|c|c|c|c|c|c|c|c|c|}
\hline \multirow{4}{*}{ Policy $^{b}$} & \multicolumn{8}{|c|}{ Modification of EMPALF $F^{a}$} \\
\hline & \multicolumn{2}{|c|}{$\begin{array}{c}\text { Linear damage } \\
\text { function }\end{array}$} & \multicolumn{2}{|c|}{$\begin{array}{c}\text { Oviposition } \\
\text { function }\end{array}$} & \multicolumn{2}{|c|}{$\begin{array}{l}\text { Immigration } \\
\text { period }\end{array}$} & \multicolumn{2}{|c|}{$\begin{array}{l}\text { Oviposition and } \\
\text { immigration }\end{array}$} \\
\hline & $\begin{array}{c}\text { Threshold } \\
\text { change }\end{array}$ & $\begin{array}{c}\text { Income } \\
\text { loss }\end{array}$ & $\begin{array}{c}\text { Threshold } \\
\text { change }\end{array}$ & $\begin{array}{l}\text { Income } \\
\text { Ioss }\end{array}$ & $\begin{array}{c}\text { Threshold } \\
\text { change }\end{array}$ & $\begin{array}{c}\text { Income } \\
\text { loss }\end{array}$ & $\begin{array}{c}\text { Threshold } \\
\text { change }\end{array}$ & $\begin{array}{c}\text { Income } \\
\text { loss }\end{array}$ \\
\hline & $\begin{array}{c}\text { Adults } / \mathrm{m}^{2} \\
\text { II }\end{array}$ & $\begin{array}{c}\$ / h a \\
\text { III }\end{array}$ & $\begin{array}{c}\text { Adults } / \mathrm{m}^{2} \\
\text { IV }\end{array}$ & $\underset{\mathrm{v}}{\$ / \mathrm{ha}}$ & $\begin{array}{c}\text { Adults } / \mathrm{m}^{2} \\
\text { VI }\end{array}$ & $\begin{array}{c}\$ / \text { ha } \\
\text { VII }\end{array}$ & $\begin{array}{c}\text { Adults } / \mathrm{m}^{2} \\
\text { VIII }\end{array}$ & $\begin{array}{l}\text { \$/ha } \\
\text { IX }\end{array}$ \\
\hline $\begin{array}{l}\mathrm{A} \\
\mathrm{B}\end{array}$ & $\begin{array}{r}+5 \\
+15\end{array}$ & $\begin{array}{l}27 \\
29\end{array}$ & $\begin{array}{r}-1 \\
-10\end{array}$ & $\begin{array}{l}17 \\
13^{e}\end{array}$ & & & & \\
\hline $\begin{array}{l}\text { C } \\
\text { D }\end{array}$ & $\begin{array}{r}+5 \\
+15\end{array}$ & $\begin{array}{r}28 \\
8\end{array}$ & $\begin{array}{r}-1 \\
-10\end{array}$ & $\begin{array}{l}10 \\
42^{e}\end{array}$ & $\begin{array}{l}\mathrm{NC}^{d} \\
-10\end{array}$ & $\begin{array}{r}0 \\
20\end{array}$ & $\begin{array}{c}f \\
-15\end{array}$ & $\begin{array}{l}12 \\
42^{e}\end{array}$ \\
\hline $\begin{array}{l}\mathrm{E} \\
\mathrm{F}\end{array}$ & $+\frac{10}{c}$ & $\begin{array}{r}25 \\
8\end{array}$ & $\begin{array}{r}-5 \\
-10\end{array}$ & $\begin{array}{l}22^{e} \\
20\end{array}$ & $\begin{array}{l}-2 \\
-5\end{array}$ & $\begin{array}{l}10 \\
15\end{array}$ & $\begin{array}{l}-10 \\
-10\end{array}$ & $\begin{array}{l}25^{e} \\
27\end{array}$ \\
\hline $\begin{array}{l}\mathrm{G} \\
\mathbf{H}\end{array}$ & $+\underset{c}{+10}$ & $\begin{array}{r}29 \\
8\end{array}$ & $\begin{array}{r}-5 \\
-15\end{array}$ & $\begin{array}{l}20^{e} \\
17\end{array}$ & $\begin{array}{r}-5 \\
-10\end{array}$ & $\begin{array}{l}10 \\
15\end{array}$ & $\begin{array}{l}-10 \\
-20\end{array}$ & $\begin{array}{l}27^{c} \\
27^{c}\end{array}$ \\
\hline I & $+\underset{c}{+15}$ & $\begin{array}{l}28 \\
30\end{array}$ & $\frac{-15}{N C^{d}}$ & $\begin{array}{c}20^{e} \\
0\end{array}$ & $\begin{array}{r}-10 \\
-5\end{array}$ & $\begin{array}{r}12 \\
2\end{array}$ & $\begin{array}{l}-20 \\
-20\end{array}$ & $\begin{array}{l}28^{c} \\
16^{c}\end{array}$ \\
\hline
\end{tabular}

a See text for explanation.

${ }^{b}$ Policies from Fig. 3.

$c$ The threshold for this policy is not reached within a reasonable range of densities $\left(0-70 / \mathrm{m}^{2}\right)$.

${ }^{d} \mathrm{NC}$, No change.

${ }^{\varepsilon}$ Use of original policy results in a low TNC level at the end of the season (TNC $=0.22-0.29$ ).

$f$ Policy D replaces policy $C$.

ment (following the second cut), the observed densities were much higher than the predicted.

Sensitivity Analysis. Comparison of simulated results to field data is the best method for evaluating a model, but in the short run, there usually are not enough observations to test all components of the model under all possible field conditions. Therefore, a sensitivity analysis is usually performed to discover how the model's policies are affected by its weakest assumptions.

In our sensitivity analysis, we took a close look at our assumptions concerning oviposition, immigration, and damage. We chose these functions for two reasons. First, we know that they are important processes. Second, although there is some uncertainty about their true forms, we had some information on which to base alternatives tested in the analysis.

Since the damage function in the model has a direct impact on the economic loss, we performed a sensitivity analysis on the function describing the impact of leafhoppers on the proportion of leaf crude protein. When we increased and decreased the slope in equation 7 by $10 \%$, we found that the best management policies suggested by the model simulations were unchanged from those given in Fig. 3. We considered different functional forms as well as changes in parameter values. The damage function (equation 7) developed by Zaky (1981) and used by us is nonlinear: the effect of additional feeding is more severe at lower than at higher leafhopper densities. We examined the importance of this assumption by fitting a linear function to Zaky's data:

$$
\mathrm{CP}(t)=42.0-0.55 \mathrm{PLH}(t) / 200
$$

where CP is percentage of leaf crude protein and PLH is density of leafhoppers. In this fit, we omitted two data points given by Zaky, since they represented higher leafhopper densities than those observed in commercial fields. Equation 11 produces a smaller proportional loss in LCP for a given density of leafhoppers than the original equation. The results of this change and other changes are summarized in Table 4 and are discussed at the end of this section.

We considered two ways in which oviposition might vary from our previous assumptions. We changed the reduction in postharvest oviposition during the first 3 days after a cut from a $100 \%$ reduction (no oviposition) to either a 50\% reduction or no reduction. To find out how the policies are influenced by the shape of the oviposition function, we substituted the following equation for equation 3 :

$$
\text { OVIP }=226.8-226.8 A^{2}
$$

where OVIP is eggs/female/physiological time and $A$ is the physiological age of the female. The total number of eggs deposited per female is the same in this equation as in equation 3 , but with this equation peak oviposition is at the beginning rather than the middle of the oviposition period.

Our previous analysis assumed that immigration occurred over a 5-day period. Because immigration could occur over a longer period, we considered an immigration period of 10 days, with $10 \%$ of the immigrants arriving per day. We looked at the change in immigration period alone and in combination with the altered oviposition function.

Increasing postharvest oviposition did not change 
Table 5. Comparison of some policies for managing E. fabae on alfalfa

\begin{tabular}{lccc}
\hline \hline \multirow{2}{*}{ Location (source) } & \multicolumn{3}{c}{ Policies $^{a}$} \\
\cline { 2 - 4 } & \multicolumn{3}{c}{ Stem height } \\
\cline { 2 - 4 } & $18 \mathrm{~cm}$ & $30 \mathrm{~cm}$ & $50 \mathrm{~cm}$ \\
\hline V'irginia (Luna 1982) & 0.4 & 1.1 & $1.8^{b}$ \\
New York (NYSCALS 1982) & 1.0 & 2.0 & 2.0 \\
Indiana (Wilson 1982) & 0.5 & 2.0 & 2.0 \\
New York (EMPALF) & $0.1-0.3$ & $0.1-0.8$ & $0.7-3.0^{d}$ \\
\hline
\end{tabular}

a Number of leafhoppers per pendular sweep. Threshold for immediately treating crop with an insecticide except as otherwise noted.

$b$ Above this threshold an early harvest is recommended, but not an insecticide application.

$c$ Based on values in Fig. 2 for all three temperature patterns.

Above these thresholds a postharvest treatment is recommended.

the management policies given in Fig. 3. The results of the other changes are summarized in Table 4. The first column in Table 4 designates the combination of threshold, tactic, and stem height we are considering where the letters refer to those on Fig. 3. For example, " $A$ " refers to the stem height of $18 \mathrm{~cm}$, a pest density of 4 adults per $\mathrm{m}^{2}$, and a postarrival treatment. Columns II and III refer to the change in policy resulting from the replacement of the nonlinear damage function, given by equation 7 , with a linear one (equation 11). The +5 in Column II indicates that the economic threshold in policy $A$ increased by 5 adults per $\mathbf{m}^{2}$. This change in threshold is small in absolute terms but large relative to the original threshold value of 4 adults per $\mathrm{m}^{2}$. The remaining entries in Column II indicate that the other thresholds are also sensitive to changes in the shape of damage function. For example, policies $B, D$, and $I$ all change by 15 adults per $\mathrm{m}^{2}$. Policies $\mathrm{F}, \mathrm{H}$, and J are eliminated by the use of the linear damage function. Hence, for stem heights of 37 and $45 \mathrm{~cm}$, the upper threshold requiring an early second harvest is no longer needed.

The third column in Table 4 gives an estimate of the consequences of choosing the wrong policy because of an error in the shape of the damage function. For example, the first entry in Column III is $\$ 27$. This indicates that if the actual loss function is the linear form (equation 11), and if we mistakenly used the policy recommended in Fig. 3, the maximum amount of net loss associated with that mistake is $\$ 27$. This value is determined by using the model to compute the income obtained with the policy given in Fig. 3, and then recomputing the model to calculate the income associated with the policy in Column II of Table 4. The remaining entries in Column III describe the maximum loss associated with the other policies. Note that the sensitivities of policies are not correlated with the losses due to using the wrong policy.

As expected, use of the linear damage function consistently increased the economic thresholds. The large values for both the increases in the thresholds and the maximum losses associated with mistaken use of the original policies indicate that the density-damage relationship for leaf crude protein is of critical importance.

The shape of the oviposition function is also very important for policy determination. Since the new function permits greater oviposition before immigrants are killed by harvesting or insecticide treatment, the economic thresholds are decreased. If the wrong policy is used, the values in Columns IV and V indicate that losses from seasonal income can be as high as 5\% and September TNC concentrations can be as low as $25 \%$ of the taproot.

With a longer immigration period the early immigrants have more time for oviposition before any control measures are taken. Column VI in Table 4 indicates that the thresholds are reduced to compensate for the earlier and greater oviposition.

Since changing the immigration period and the oviposition function both result in lower thresholds due to increases in oviposition prior to control, changing both simultaneously should lower thresholds as much or more. The results in Columns VIII and IX support this hypothesis. Use of the results from the original model when the immigration period is actually 10 days and the peak oviposition is at the beginning of the oviposition period can result in $5 \%$ losses in income and drastic reductions (up to 40\%) in the TNC levels at the end of the season.

Comparison to Current Recommendations. The validation results presented in Fig. 4 through 6 only examine the relationship between predicted population densities and those observed. Another important measure of a management model is the reasonableness and effectiveness of the policies it suggests (Welch et al. 1981). Therefore, we compared the model's policies with current recommendations for leafhopper control.

Table 5 presents some of the policies from three of the currently recommended guidelines (Luna 1982, NYSCALS 1982, Wilson 1982). All of them use an economic threshold of 0.2 leafhoppers per pendular sweep just after a harvest. Using the method of Fleischer et al. (1982) for converting densities per $\mathrm{m}^{2}$ to values per sweep, we can compare our results to these three guidelines. Our threshold under a medium temperature pattern for stubble after the first cut (Table 3 ) is 0.1 adults per $\mathrm{m}^{2}$. But above a height of $18 \mathrm{~cm}$ for the second crop, our policies are much different (Table 5). In Table 5, all of the thresholds tend to increase with stem height, but those in the current guidelines level off at 2 leafhoppers per sweep above $30 \mathrm{~cm}$ (NYSCALS 1982, Wilson 1982) or 1.8 leafhoppers per sweep above $40 \mathrm{~cm}$ (Luna 1982). As Fig. 2 demonstrates, our thresholds tend to increase exponentially up to the second harvest. We realize that the difference shown in Table 5 may be due to differences in the regions studied or in the in- 
secticides recommended, but there are four fundamental differences which these two factors should not influence.

First, our policies take into account damage to all crops of alfalfa, whereas the other guidelines are based only on damage to a single crop. This is one reason why our thresholds are lower in some cases. Second, we developed separate policies for managing the leafhopper on each of the three crops; we assume that the other recommendations in Table 5 are used primarily for the second crop. Third, all of our policies are based only on samples of adult immigrants, not their offspring, but sampling is not limited to the adult stage in the other guidelines. Management of high densities of adults (above the thresholds) before nymphs develop is important if damage is to be prevented. Fourth, NYSCALS (1982) and Wilson (1982) used only a single, dynamic threshold, with the traditional postarrival treatment as the control tactic. Luna (1982) considered both early harvests and postarrival treatments as tactics and used two thresholds for alfalfa taller than $35 \mathrm{~cm}$. In contrast, we developed multiple economic thresholds for several alfalfa growth stages and evaluated five or more control tactics for each situation.

\section{Discussion}

The comparisons of management policies suggest that systems analysis can be useful in alfalfa forage production. Because climate has so much influence on the development and implementation of strategies, a general model such as ours provides a useful and inexpensive tool for determining policies and investigating their consequences in any climatic region. It also allows the user to study the effects of a range of control tactics, including timing of insecticide treatments, timing of harvests, and method of harvesting. In general, our results demonstrate the value of a cutting schedule that optimizes high-quality yields and adequate carbohydrate reserves. The harvesting method should produce a low and clean stubble to prevent survival and development of damaging numbers of leafhoppers, as recommended by Simonet and Pienkowski (1979). In the future, methods such as chopping for hay crop silage should be evaluated for use as a control tactic.

Because of the uncertainty associated with weather, there is a certain amount of risk associated with the management policies. For instance, Fig. 2 shows the best economic thresholds as a function of three seasonal weather patterns. Unfortunately, management decisions must be made before the weather for the rest of the season is known. The most important risk involved in management of the leafhopper on alfalfa is the possibility of winter kill following loss in TNC in the taproot. The sensitivity analysis showed that uncertainty in our knowledge of several biological processes influences the level of risk in decision- making. In addition, a brief study of the use of policies based on a medium temperature pattern in simulations under a high temperature pattern indicated that losses in TNC were more important than reductions in income. These losses in TNC were most acute when early second harvests were made under the warmer conditions.

The best way to minimize the risk of major losses to TNC is to use weather data appropriate for the particular area where the model is being applied, and to update the weather data as it becomes available. The first step would be to make a decision based on expected weather after the immigration. If after the management action is taken the weather becomes substantially warmer or cooler than average, the situation could be reevaluated. Using all the available weather and scouting information, the model can be recomputed to determine if different control actions should be taken.

However, an overemphasis on avoiding risk results in lower incomes during the majority of years that are close to the average (or cooler) in terms of temperature. Maximization of mean income over many years would not usually involve a procedure for updating the model. For example, in central New York, the policies resulting from simulations with the medium temperature pattern are probably the best to use in most years. Although the model results suggest that cutting the second crop early to manage high densities of leafhoppers would be a bad tactic under the high temperature pattern, this type of pattern only occurs during a few years. In addition, extending the length of the third crop's growth period by a week would make this policy less sensitive to factors, such as temperature, that affect TNC levels (Onstad and Shoemaker 1984). This means that the policies presented in Fig. 3 and Table 3 might be the best compromise for this region, given our current state of knowledge. This compromise is one solution to the problem involving the trade-off between high risk and maximum expected income under random weather conditions.

Another source of risk is the uncertainty associated with the duration of immigrations. We know from the sensitivity analysis that the length of the immigration period has a significant effect on the value of management policies. To reduce errors in decision-making, sampling should be done as frequently as possible using a procedure such as the one developed by Fleischer et al. (1982). Ideally, the policies should incorporate the density of eggs at the time of sampling into a multidimensional economic threshold for both adults and eggs. Unfortunately, sampling for eggs is not feasible, so we are left with approximations in terms of adults only, and concomitant assumptions concerning immigration period.

In our evaluation of the model and its results, we emphasized the quantitative aspects. However, the qualitative information gained from the model 
must not be ignored. First, as previously stated, the spatial distribution of the leafhopper population in the alfalfa field is important. It influences sampling as well as the calculation of economic thresholds. Second, management must consider not only losses in leaf crude protein, but also losses in the carbohydrate reserve level at the end of the season. Unfortunately, the latter is not easily defined in economic terms. Third, future weather after an immigration has a major effect on the leafhopper-alfalfa system. It determines the amount of damage caused during the season and influences the risk involved in decision-making. Fourth, management decisions should be made as soon as possible after an immigration. This provides the opportunity to control adult immigrants and limit their ovipositing. It also gives the farmer adequate time to prepare for the necessary actions at the next harvest. Fifth, even when sampling, decision-making, and insecticide treatment are performed perfectly, some damage will be incurred as long as immigrations occur over periods of several days. The damage by the adults before they are controlled cannot be prevented, and the offspring, which cannot always be killed as eggs, will cause some damage before they are eventually controlled. Finally, the model's results indicated that the timing of the second harvest can be important to the management of infestations begun on the second crop. This observation corresponds to the one made by Pienkowski and Medler (1962).

Our analysis indicates there is a need for more validation data that can be used to evaluate the management policies, not just the population $d y-$ namics. There is also a need for additional quantitative data regarding leafhopper mortality and damage to alfalfa. When these data become available, we will improve our understanding of the leafhopper-alfalfa ecosystem and have more confidence in the model. Until then, the model can serve as a useful tool for dealing with the complexity of the system, thereby providing a foundation for research and management of the potato leafhopper on alfalfa.

\section{Acknowledgment}

We thank Donald Simonet, William Lamp, Arthur Hower, and Grayson Brown for their assistance. We also thank Ray Carruthers, Gary Fick, Donald Simonet, William Ruesink, and an anonymous reviewer for their thoughtful criticisms of this paper. This project was supported in part by funds from the Environmental Protection Agency (71-59-248-1-2-039-1) and USDA (83CRSR-2-1000).

\section{References Cited}

Bula, R. J., and T. R. Hintz. 1978. Estimating alfalfa yields from stem height. Proc. 15th Annu. Northeast Invit. Alf. Insect Conf. Purdue University Dept. of Entomology, West Lafayette, Indiana, pp. 27-31.
Cherry, R. H., K. A. Wood, and W. G. Ruesink. 1977. Emergence trap and sweep net sampling for adults of the potato leafhopper from alfalfa. J. Econ. Entomol. 70: 279-282.

Decker, G. C., C. A. Kouskolekas, and R. J. Dysart. 1971. Some observations on fecundity and sex ratios of the potato leafhopper. Ibid. 64: 1127-1129.

DeLong, D. M. 1938. Biological studies on the leafhopper Empoasca fabae as a bean pest. U.S. Dep. Agric. Tech. Bull. 618 .

1971. The bionomics of leafhoppers. Annu. Rev. Entomol. 16: 179-210.

Fick, G. W. 1981. ALSIM1 (Level 2) User's Manual. Cornell Univ., Dept. of Agronomy Mimeo 81-35.

Fleischer, S. J., W. A. Allen, J. M. Luna, and R. L. Pienkowski. 1982. Absolute-density estimation from sweep sampling, with a comparison of absolutedensity sampling techniques for adult potato leafhopper in alfalfa. J. Econ. Entomol. 75: 425-430.

Flinn, P. W. 1981. Effects of density and age class of the potato leafhopper on seedling alfalfa development. M.S. thesis, Pennsylvania State University, State College.

Gauthier, N. L. 1978. Third cutting alfalfa insect control study. Insectic. Acaric. Tests 3: 113-114.

Hower, A. A., and R. A. Byers. 1977. The potato leafhopper reduces alfalfa quality. Sci. Agric. 24: 1011.

Huggans, J. L., S. Quisenberry, K. Jackson, and D. Reber. 1980. Alfalfa weevil larva control. Insectic. Acaric. Tests 5: 120-121.

Kieckhefer, R. W., and J. T. Medler. 1964. Some environmental factors influencing oviposition by the potato leafhopper, Empoasca fabae. J. Econ. Entomol. 57: 482-484.

1966. Aggregations of the potato leafhopper in alfalfa fields in Wisconsin. Ann. Entomol. Soc. Am. 59: 180182

Ladd, T. L., Jr., and W. A. Rawlins, 1965. The effects of the feeding of the potato leafhopper on photosynthesis and respiration in the potato plant. J. Econ. Entomol. 58: 623-628.

Luna, J. M. 1982. Integrated pest management of potato leafhopper in alfalfa. Va. Polytech. Inst. and State Univ., Dept. of Entomol. Special Publ.

Manetsch, T. J. 1976. Time-varying distributed delays and their use in aggregative models of large systems. IEEE Trans. Sys. Man. Cybern., Vol. SMC-6, No. 8: 547-553.

Medler, J. T., R. L. Pienkowski, and R. W. Kieckhefer. 1966. Biological notes on Empoasca fabae in Wisconsin. Ann. Entomol. Soc. Am. 59: 178-180.

New York State College of Agriculture and Life Sciences. 1982. Cornell recommends for field crops. Cornell University, Ithaca, N. Y.

Onstad, D. W., and G. W. Fick. 1983. Predicting crude protein, in vitro true digestibility, and leaf proportion in alfalfa herbage. Crop Sci. 23: 961-964.

Onstad, D. W., and C. A. Shoemaker. 1984. Management of alfalfa and the alfalfa weevil (Hypera postica): an example of systems analysis in forage production. Agric. Syst. 14: 1-30.

Pienkowski, R. L., and J. T. Medler. 1962. Effects of alfalfa cuttings on the potato leafhopper, $E \mathrm{E}$ poasca fabae. J. Econ. Entomol. 55: 973-978.

Simonet, D. E. 1978a. Population studies of the potato leafhopper, Empoasca fabae (Harris) on alfalfa, Medicago sativa L. Ph.D. Dissertation, Virginia Polytechnic Institute and State University, Blacksburg. 
1978b. Alfalfa foliar sprays for potato leafhopper control. Insectic. Acaric. Tests 3; 116-117.

Simonet, D. E., and R. L. Pienkowski. 1979. Impact of alfalfa harvest on potato leafhopper populations with emphasis on nymphal survival. J. Econ. Entomol. 72: 428-431.

1980. Temperature effect on development and morphometrics of the potato leafhopper. Environ. Entomol. 9: 798-800.

Simonel, D. E., R. L. Pienkowski, D. G. Martinez, and R. D. Blakeslee. 1978. Laboratory and field evaluation of sampling techniques for the nymphal stages of the potato leafhopper on alfalfa. J. Econ. Entomol. 71: 840-842.

Welch, S. M., B. A. Croft, and M. F. Michels. 1981.
Validation of pest management models. Environ. Entomol. 10: 425-432.

Wilson, M. C. 1982 . Improving alfalfa forage quality: how to detect and manage the potato leafhopper problem. Certified Alfalfa Seed Council, Woodland, Calif.

Zaky, S. H. 1981. Damage potential of potato leafhopper nymphs, Empoasca fabae Harris (Homoptera: Cicadellidae) on established stand alfalfa. Ph.D. dissertaton, Pennsylvania State University, State College.

Recelved for publication 5 October 1983; accepted 23 April 1984. 